\title{
To conference or not to conference
}

Every 6 months, every year or every 2 - 3 years, organisations in obstetrics and gynaecology meet throughout the world. These can be international organisations that deal with all topics, such as the International Federation of Gynecology and Obstetrics (FIGO), or societies that deal with a specific topic, such as the International Society for the Study of Hypertension in Pregnancy (ISSHP), the International Urogynaecology Association (IUGA), or the International Continence Society (ICS). Such meetings ventilate ideas and stimulate discussion.

Going to such conferences offers the chance to discover what is current and what is controversial.

In the era of the internet (by means of which we are communicating now), is that really necessary? At the touch of several buttons, a person can travel throughout the world, from Cape to Cairo, from Jakarta to Istanbul, from San Diego to Beijing, from Tashkent to Cancun, either to read articles published, international or national guidelines, or even to read the proceeds from meetings and conferences.

Is there any real advantage of going to conferences in the era of electronic information? Yes.

If you go to a meeting you can hear an author of original research or a collaborator of a multicentre trial or an author of a Cochrane review or other guideline actually speak and, especially, answer direct questions. Sometimes it is through the responses to welldirected questions that a real flavour of the truth emerges, as it can, incidentally, in the correspondence section of journals. Sometimes it is through casual comments and asides made during conference presentations that strongly held beliefs are revealed, a reality which is not always present in the formal diplomatic phrases and sentences of the printed word.

People - experts - who speak in conferences talk, in relation to a subject, of treatments or techniques they would never use, and why, or of treatments, interventions or tests which they feel have been rejected too easily, without due consideration, and now require revision. They talk with a freedom and a range that may not be suited to the confined space of a paper's introduction or discussion, or to the rigid format of a review.

But it is not only established experts at conferences who provide information; it is the other conference goers, often not high-ranking academics, who, in conversation, provide assistance to those who happen to listen. Clear thinking and a wealth of experience come from those who may not have shone brightly on the world stage. Two colleagues recounted advice given over conference coffee - the one of obligatory consent for laparoscopy including warning of laparotomy and visceral injury long before it became popular, the other of advice to use a subcutaneous pencil drain in all morbidly obese patients to avoid wound breakdown and infection. These very useful pieces of advice were given as the discussion following a presentation continued over sandwiches - conferences are stimulants.

International meetings are not the only conferences; almost every country has its own meetings, and again these meetings may either deal with the entirety of obstetrics and gynaecology, such as those held by the All India Society of Obstetrics and Gynaecology, or specific topics, such as the meetings of the Upper Egypt Society of Fertility.
National and local meetings have a distinct advantage over international ones - they are easier to get to; local travel is more affordable, while international travel and accommodation are expensive. While many gynaecologists are wealthy, there are also many, and other related practitioners, who are not. Traveling locally, knowing how to acquire low-cost accommodation or even staying with colleagues is more achievable.

Funding for international meetings may, however, be supported by local institutions such as universities, departments, hospitals or societies, and of course by commerce - 'the trade'. Sometimes funds available from institutions and societies for subsidising conference registration, foreign or national travel and accommodation are not known about and are not accessed - it's strange, says a funder, that not many people applied. It is, therefore, the responsibility of all who know of such resources to advertise them and make sure that others, the many who require them, know of the monies available and how to access them.

Funding from commerce may be complicated. Funding for an individual may follow research on a particular product. If a medically associated person has performed research that was independently reviewed and published, it is perhaps not unreasonable that subsidised travel and conference attendance may follow. However, if financial assistance for travel has contributed to the endorsement and validation of interventions with minimal benefit, or has encouraged a healthcare system to unnecessarily acquire expensive equipment or unhelpful medical products, that would be a very unfortunate consequence of commercially subsidised conference attendance.

The support by commerce of the conference itself is a natural element of academic activity. We do not live in a socialistic idyll, and inevitably the manufacturers of beautiful and costly ultrasound machines, or of dietary supplements that claim to decrease candida infections, are always present. There is no obligation or requirement to purchase their products, and their presence will support the attendance of guest speakers and those who apply for assistance.

What of the topics of the conference itself? A hasty perusal of a printed list of subjects quickly shows whether the attempt to find the wherewithal to register and travel, and the time off work, are justified, although we are all careless readers and sometimes a second look is worthwhile.

Conferences and meetings, international, national and local, general or specific, are worthwhile. They stimulate discussion, questioning and leadership. Yes, meetings and presentations can be tedious. Monotonous and long-winded questions from the floor can be frustrating and tedious also. But among the presentations and coffee conversations there is stimulation, scholarship and often a realisation that from all levels of our profession and associated specialties come insights and experience that encourage us to see things differently.

\section{William Edridge Editor}

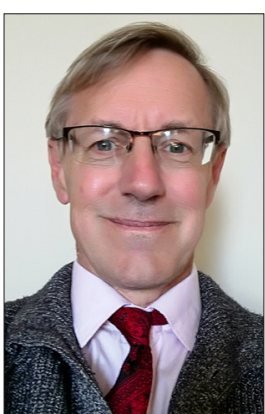

S Afr J Obstet Gynaecol 2017;23(3):75. DOI:10.7196/SAJOG.2017.v23i3.1287 